\title{
Atypical lymphocytic lobular panniculitis: an overlap condition with features of subcutaneous panniculitis-like T-cell lymphoma and lupus profundus
}

\author{
Alice He, Shawn G Kwatra, Najiyah Kazi, Ronald J Sweren
}

Department of Dermatology, Johns Hopkins University School of Medicine, Baltimore, Maryland, USA

\section{Correspondence to} Dr Shawn G Kwatra skwatra1@jhmi.edu

Accepted 21 October 2016
CrossMark

To cite: He A, Kwatra SG, Kazi N, et al. BMJ Case Rep Published online: [please include Day Month Year] doi:10.1136/bcr-2016215335

\section{DESCRIPTION}

A woman aged 45 years presented for evaluation of skin lesions. She reported an 8-9-year history of occasionally tender, waxing-and-waning skin nodules refractory to dapsone, prednisone and methotrexate. Examination revealed multiple indurated subcutaneous nodules distributed on the upper extremities, with scattered patches of lipoatrophy in areas of nodule regression (figure 1). Her medical history was unremarkable; CBC and CMP were within normal limits, with no history of radiotherapy or evidence of internal organ involvement. She had a positive ANA titre (1:160, speckled), but negative anti-dsDNA, anti-Smith, anti-Ro and anti-La antibodies.

Differential diagnosis included erythema nodosum (EN), erythema induratum of Bazin (EIB), lupus profundus (LP) and cutaneous lymphoma.

Initial wedge biopsy in 2008 disclosed a predominantly lobular panniculitic process with some septal involvement (figure 2A). Broad zones of necrosis were present (figure 2B). The infiltrate consisted of a pleomorphic population of lymphocytes with occasional larger atypical lymphocytes (figure 2C). There were foci of adipocyte rimming by the atypical lymphocytes (figure 2C). Immunophenotyping revealed predominance of CD3 + T cells with some CD20+ B-cell aggregates. The atypical cells stained CD4 and CD8 in approximately equal ratios. TIA-1 was positive in many of the atypical cells but not prominently enough to render a diagnosis of cytotoxic T-cell lymphoma. T-cell receptor PCR studies showed polyclonality. Subsequent biopsies performed annually after treatment with prednisone in 2008 and 2010, dapsone in 2009 and methotrexate in 2012 showed very similar pathological and molecular features. Adipocyte rimming and TCR polyclonality persisted.

EN is characterised by subcutaneous nodules on the lower extremities in association with elevated erythrocyte sedimentation rate (ESR) and C reactive protein (CRP), influenza-like prodrome preceding nodule formation and self-limiting course. ${ }^{1}$ Histologically, EN shows a mostly septal panniculitis with radial granulomas. ${ }^{1} \mathrm{EN}$ was ruled out on the basis of normal ESR (6) and CRP $(<0.1)$, chronic relapsing course and predominantly lobular panniculitis process histologically. EIB typically presents with violaceous nodules located on the posterior lower extremities, with arms rarely affected, of patients with a history of tuberculosis (TB). ${ }^{2}$ Histologically, EIB shows granulomatous inflammation with focal necrosis, vasculitis and septal fibrosis. ${ }^{2}$ Our patient had no evidence or history of TB infection and presented with nodules of a different clinical morphology.

Ultimately, this constellation of histological and immunophenotypic findings showed an atypical panniculitic T-lymphocytic infiltrate. Although the lesion showed a lobular panniculitis with features that could be seen in subcutaneous panniculitis-like T-cell lymphoma (SPTCL), the presence of plasma cells, absence of CD8 and TIA restriction and T-cell polyclonality did not definitively support that

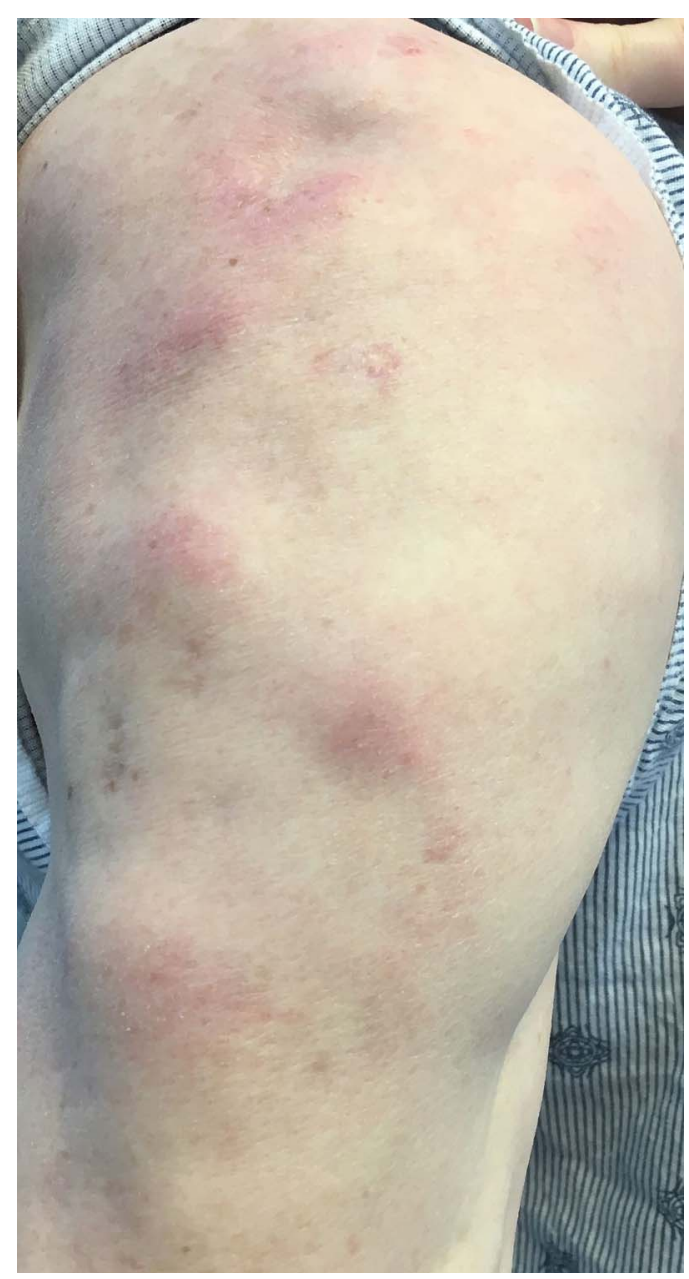

Figure 1 Multiple erythematous subcutaneous nodules distributed over the patient's right arm. 


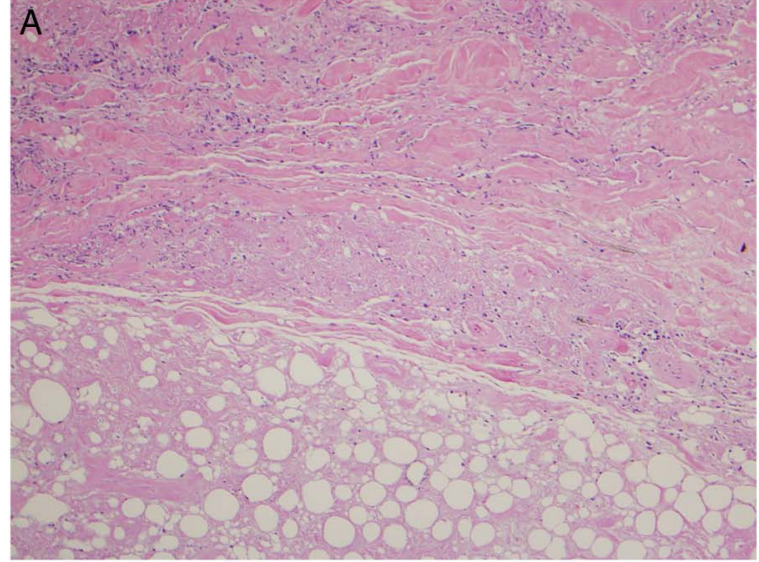

B

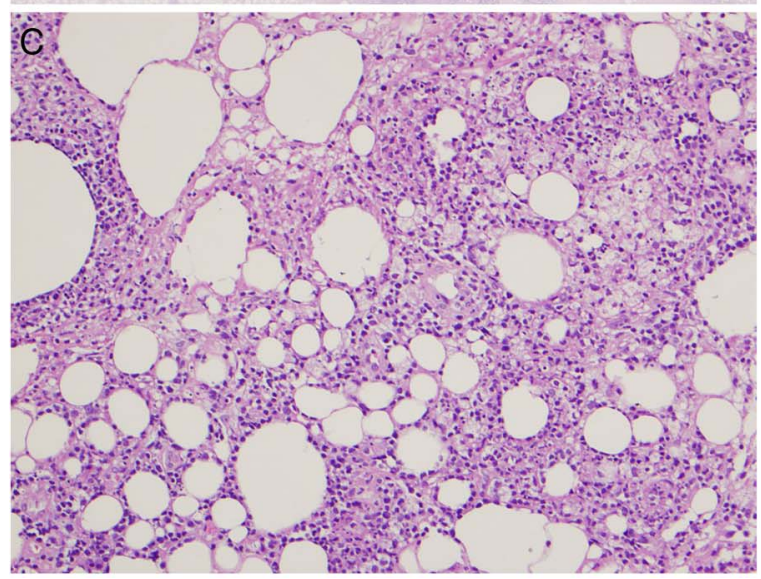

Figure 2 Pathology images from an excisional wedge biopsy of a subcutaneous nodule. (A) A low-power image reveals a predominantly lobular panniculitis with some septal involvement $(\mathrm{H} \& \mathrm{E}, \times 20$ magnification). (B) There are foci of fat necrosis as well as broad zones of coagulation necrosis involving the fibrous septae $(\times 100)$. (C) The lymphocytic infiltrate is pleomorphic, comprised predominantly of small-to-intermediate-sized lymphocytes, with occasional large atypical cells. There are foci of rimming of adipocytes by atypical lymphocytes $(\times 200)$.

diagnosis. There were also histological findings consistent with LP, including clusters of B-lymphocytes, polyclonal T cells and clinically, resolution of nodules with lipoatrophy. However, the infiltrate did neither show significant mucinous ground substance nor panniculitic hyalinisation typical of LP. Of note, the pathological feature of adipocyte rimming by atypical lymphocytes is found in lupus and SPTCL.

LP is a rare presentation of cutaneous lupus erythematosus that presents similarly to SPTCL. Cases have been reported on patients who present with overlapping features of SPTCL and LP, but who also lack clear-cut diagnostic features of either. It has thus been suggested that perhaps patients with LP and SPTCL overlap may represent a distinct disease entity known as 'atypical lymphocytic lobular panniculitis', as we suspect is the case for our patient.

The patient was prescribed hydroxychloroquine. After 3 months, she reported improvement in lesion regression without formation of new nodules. She is tolerating hydroxychloroquine well without major side effects.

\section{Learning points}

- The differential for subcutaneous nodules is wide, and requires inquiring about location of nodules, prodromes, medical history and progression course; blood work and ultimately biopsy of the nodule should be part of the diagnostic work-up.

- Subcutaneous panniculitis-like T-cell lymphoma (SPTCL) and lupus profundus (LP) present very similarly, as both are characterised by multiple subcutaneous nodules; they are primarily distinguished histologically, although the pathological feature of adipocyte rimming by atypical lymphocytes can be seen in both conditions.

- Patients who present with both overlapping features of SPTCL and LP, but yet lack diagnostic features of either, may be categorised into a separate disease entity, known as 'atypical lymphocytic lobular panniculitis'.

Contributors $\mathrm{AH}$ substantially contributed to the analysis and interpretation of data for the work, drafted the work, approved the final version and is accountable for all aspects of the work. SGK substantially contributed to the design and acquisition of data for the work, revised the work, approved the final version and is accountable for all aspects of the work. NK substantially contributed to the acquisition of data for the work, revised the work, approved the final version and is accountable for all aspects of the work. RJS substantially contributed to the conception and acquisition of data for the work, revised the work, approved the final version and is accountable for all aspects of the work.

Competing interests None declared.

Patient consent Obtained.

Provenance and peer review Not commissioned; externally peer reviewed.

\section{REFERENCES}

1 Blake T, Manahan M, Rodins K. Erythema nodosum - a review of an uncommon panniculitis. Dermatol Online J 2014;20:3.

2 Babu AK, Krishnan P, Dharmaratnam AD. Erythema induram of bazin-tuberculosis in disguise. J Dermatol Dermatol Surg 2015;19:66-8.

3 Bosisio F, Boi S, Caputo V, et al. Lobular panniculitis infiltrates with overlapping histopathologic features of lupus panniculitis (Lupus Profundus) and subcutaneous T-cell lymphoma: a conceptual and practical dilemma. Am J Surg Pathol 2015:39:206-11 
Copyright 2016 BMJ Publishing Group. All rights reserved. For permission to reuse any of this content visit http://group.bmj.com/group/rights-licensing/permissions.

BMJ Case Report Fellows may re-use this article for personal use and teaching without any further permission.

Become a Fellow of BMJ Case Reports today and you can:

- Submit as many cases as you like

- Enjoy fast sympathetic peer review and rapid publication of accepted articles

- Access all the published articles

- Re-use any of the published material for personal use and teaching without further permission

For information on Institutional Fellowships contact consortiasales@bmjgroup.com

Visit casereports.bmj.com for more articles like this and to become a Fellow 